\title{
EFFECTS OF INVASIVE JAPANESE KNOTWEED ON DIVERSITY AND STRUCTURE OF SOIL NEMATODE COMMUNITIES
}

\author{
Marek Renčo ${ }^{1}$, Andrea Čerevková ${ }^{1}$, Nicola Sasanelli ${ }^{2}$ \\ ${ }^{1}$ Institute of Parasitology SAS, Košice, Slovakia, e-mail: renco@saske.sk \\ ${ }^{2}$ Institute for Plant Protection, C.N.R., Bari, Italy
}

\begin{abstract}
In this study we investigated the communities of soil nematodes in the forest habitats invaded and uninvaded by Fallopia japonica (Houtt.) Ronse Decr., in Tatra National Park, Slovakia. We found that invasion by $F$. japonica altered nematode communities and their structures. Total nematode abundance, species number and nematode biomass were significantly lower in invaded than uninvaded plots, but species diversity remained unaffected throughout the study. The overall abundance of all nematode trophic groups well represented the negative impact of $F$. japonica invasion on soil food webs, supported by low values of all maturity indices, a structural index and the Jaccard index of faunal similarity. A weighted faunal analysis similarly characterized the food webs of invaded plots as poorly developed or highly disturbed, with bacterial decomposition and a low $\mathrm{C} / \mathrm{N}$ ratio. Our findings thus suggest that dense plots of knotweed simplify the structural complexity of the soil environment by reducing the richness of plant species, which may have contributed to the negative changes in the structures of the nematode communities.
\end{abstract}

\section{Introduction}

Fallopia japonica (Japanese knotweed) invasions have repeatedly been demonstrated to have a negative impact on the species richness and diversity of native plants [6,7]. Studies of knotweed invasions, however, rarely address impacts on soil metazoans such as nematodes [2], which are probably the most well-studied group of soil organisms with excellent indicative characteristics [3].

We used soil nematodes as representatives of soil invertebrates since they are considered to the most abundant metazoans that can be found in almost all environments, under diverse climatic conditions and habitats [8].

Soil nematodes utilise plant resources from both litter inputs and root exudates, drive important ecosystems functions and comprise several specific trophic groups, including bacteria, fungi and plant feeding as well as carnivores and omnivores. Therefore, nematodes serve as valuable biological indicators and could provide interesting information on how Japanese knotweed invasion affects soil food webs.

\section{Materials and methods}

We established ten independent plots and collected soil core samples for characterizing the nematode communities in ruderal habitats of Tatra National Park invaded (five plots, Fig. 1a INV) and uninvaded (five plots, Fig. 1b - UNI) by F. japonica. The soil samples were randomly collected from the 10-15 cm layer in each plot using a hand spade on 17 June 2017, 2018 and 2019 , for a total of 30 samples (five plots $\times$ two sites $\times$ three sampling years). Extracted nematodes were heat killed, fixed and microscopically identified to the genus level. The evaluation 
of nematode communities was based on assignation of nematode species to the trophic groups (bacterivores, fungivores, plant feeders, predators and omnivores) [8]; to the "colonizer-persister (c-p) scale" (1-5) based on their $\mathrm{r}$ and $\mathrm{k}$ characteristics [1] and computation of several community indices e.g. the Shannon-Weaver diversity index (H'spp) [5], the Jaccard similarity index (Js) [4], the maturity index (MI) [1] or the enrichment index (EI) [3]. The statistical analyses were performed separately for each plot, and data were compared between the INV plots and the UNI control plots. All nematological data, including the indices, were calculated as means for the individual plots and sampling years. A factorial analysis of variance was used, and means were compared using Tukey's honestly significant difference (HSD) post hoc test $(\mathrm{P}<0.05 ; \mathrm{P}<0.01)$ of the PlotIt program Ver 3.2 (Stat Soft). Data were log-transformed before analysis to improve normality.

a

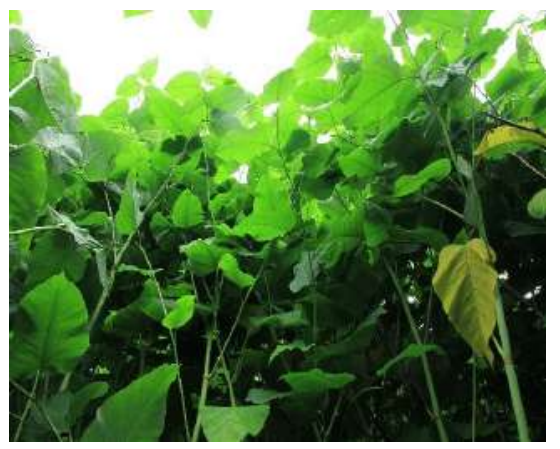

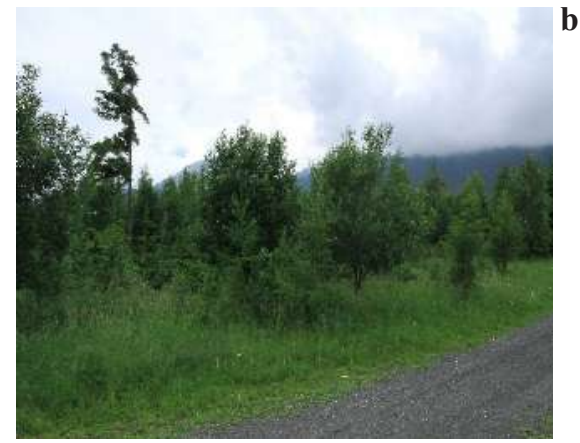

b

Figure 1. Plot invaded (a) and uninvaded (b) by $F$. japonica in the High Tatras

\section{Results and conclusion}

The response of the nematode communities to $F$. japonica invasion did not differ among sampling years but differed considerably between the INV and UNI plots. The mean number of species was significantly lower in the INV than in the UNI plots, but species diversity did not differ significantly between the plots (Table 1). Total nematode abundance also differed significantly between the INV and UNI plots (HSD, $\mathrm{P}<0.01 ; \mathrm{P}<0.05$ ) (tab. 1). Mean nematode abundance was significantly higher in the UNI than in the INV plots in all sampling years.

Additionally, The HSD test indicated that the establishment of $F$. japonica was negatively associated with all maturity indices (MI, PPI and $\sum$ MI), SI and total nematode biomass in the INV plots throughout the study $(\mathrm{P}<0.01 ; \mathrm{P}<0.05)$ (Table 1$)$. The Jaccard index of faunal similarity ranged from 55.8 to $63.2 \%$.

The nematode communities of the INV and UNI plots were represented by all trophic groups. Bacterivores were the most diverse trophic group in the study, followed by plant feeders, omnivores, predators and fungivores.

The total abundance of all trophic groups was generally lower in the INV than the UNI plots throughout the study (tab. 2) 
Table 1. Mean total nematode abundance, species number, ecological and functional indices associated with knotweed invaded and uninvaded sites during study period $(n=5)$

\begin{tabular}{|c|c|c|c|}
\hline & Uninvaded & Invaded & Significance HSD test \\
\hline \multicolumn{4}{|c|}{2017} \\
\hline Nematode abundance & $1093.3 \pm 114.5$ & $484.9 \pm 64.2$ & $* * 1$ \\
\hline Number of species & $48.4 \pm 3.6$ & $39.0 \pm 1.9$ & $*$ \\
\hline Species diversity index (H'spp) & $3.14 \pm 0.09$ & $3.11 \pm 0.05$ & -- \\
\hline Maturity index & $2.26 \pm 0.15$ & $1.97 \pm 0.14$ & $* *$ \\
\hline Plant parasitic index & $2.58 \pm 0.10$ & $2.18 \pm 0.17$ & $* *$ \\
\hline Summ maturity index & $2.34 \pm 0.14$ & $2.06 \pm 0.13$ & * \\
\hline Enrichment Index & $69.9 \pm 8.6$ & $66.7 \pm 5.1$ & -- \\
\hline Structure Index & $67.5 \pm 2.1$ & $42.5 \pm 11.3$ & $* *$ \\
\hline Channel index & $16.7 \pm 6.7$ & $13.7 \pm 6.6$ & -- \\
\hline Total nematode biomass (mg) & $3.44 \pm 0.96$ & $0.94 \pm 0.32$ & $* *$ \\
\hline \multirow{2}{*}{\multicolumn{4}{|c|}{ Jaccard index of similarity (\%) }} \\
\hline & & & \\
\hline Nematode abundance & $1171.5 \pm 157.9$ & $492.9 \pm 205.2$ & $*$ \\
\hline Number of species & $39.6 \pm 2.7$ & $32.2 \pm 2.0$ & $*$ \\
\hline Species diversity index (H'spp) & $3.08 \pm 0.08$ & $2.91 \pm 0.11$ & -- \\
\hline Maturity index & $2.24 \pm 0.17$ & $2.02 \pm 0.05$ & $*$ \\
\hline Plant parasitic index & $2.65 \pm 0.18$ & $2.21 \pm 0.11$ & $* *$ \\
\hline Summ maturity index & $2.33 \pm 0.13$ & $2.15 \pm 0.14$ & $*$ \\
\hline Enrichment Index & $73.3 \pm 4.5$ & $69.9 \pm 5.4$ & -- \\
\hline Structure Index & $68.3 \pm 8.5$ & $52.6 \pm 5.7$ & $*$ \\
\hline Channel index & $15.5 \pm 7.3$ & $7.05 \pm 5.1$ & -- \\
\hline Total nematode biomass (mg) & $3.79 \pm 1.42$ & $1.11 \pm 0.51$ & $* *$ \\
\hline \multirow{2}{*}{\multicolumn{4}{|c|}{ Jaccard index of similarity (\%) }} \\
\hline & & & \\
\hline Nematode abundance & $924.8 \pm 90.5$ & $507.4 \pm 86.6$ & $*$ \\
\hline Number of species & $48.8 \pm 3.7$ & $38.0 \pm 4.2$ & -- \\
\hline Species diversity index (H'spp) & $3.27 \pm 0.14$ & $3.05 \pm 0.10$ & -- \\
\hline Maturity index & $2.30 \pm 0.13$ & $1.99 \pm 0.08$ & $* *$ \\
\hline Plant parasitic index & $2.64 \pm 0.08$ & $2.15 \pm 0.24$ & $*$ \\
\hline Summ maturity index & $2.37 \pm 0.10$ & $2.10 \pm 0.19$ & -- \\
\hline Enrichment Index & $68.4 \pm 4.2$ & $69.6 \pm 9.3$ & -- \\
\hline Structure Index & $67.5 \pm 6.4$ & $49.8 \pm 11.8$ & $*$ \\
\hline Channel index & $16.6 \pm 2.7$ & $12.9 \pm 77.2$ & -- \\
\hline Total nematode biomass (mg) & $3.20 \pm 2.70$ & $1.15 \pm 0.46$ & $* *$ \\
\hline Jaccard index of similarity (\%) & \multicolumn{2}{|c|}{56.1} & \\
\hline
\end{tabular}


In conclusion, our study found that $F$. japonica invasion had a negative impact on the native plant communities and on the structure of soil nematode communities during the three years of our study. The impact of knotweed on these communities did not differ among sampling years, indicating a persistent disturbance of the ecosystem and soil food webs in comparison to the uninvaded control plots. Overall nematode abundance and nematode biomass were significantly lower in invaded than in uninvaded plots, a weighted faunal analysis characterized the food webs of invaded plots as poorly developed or highly disturbed with prevailed bacterial decomposition pathway.

Table 2. Mean total abundance of nematode trophic groups associated with knotweed invaded and uninvaded sites during study period $(n=5)$

\begin{tabular}{|l|c|c|c|}
\hline \multicolumn{5}{|c|}{ Uninvaded } & Invaded & Significance HSD test \\
\hline \multicolumn{3}{|c|}{$\mathbf{2 0 1 7}$} \\
\hline Bacterial feeders & $2504.9 \pm 345.2$ & $1329.8 \pm 159.2$ & $* * 1$ \\
\hline Predators & $183.0 \pm 35.9$ & $61.0 \pm 29.9$ & $*$ \\
\hline Fungal feeders & $420.5 \pm 111.3$ & $292.1 \pm 88.7$ & $*-$ \\
\hline Omnivores & $550.6 \pm 126.7$ & $172.2 \pm 53.8$ & $* *$ \\
\hline Plant feeders & $1807.7 \pm 428.8$ & $569.7 \pm 188.4$ & $* *$ \\
\hline \multicolumn{4}{|c|}{$\mathbf{2 0 1 8}$} \\
\hline Bacterial feeders & $2787.4 \pm 259.7$ & $1307.2 \pm 199.5$ & $*$ \\
\hline Predators & $231.1 \pm 59.7$ & $134.9 \pm 31.7$ & $* *$ \\
\hline Fungal feeders & $681.3 \pm 156.7$ & $116.3 \pm 47.6$ & $*$ \\
\hline Omnivores & $498.1 \pm 121.0$ & $184.2 \pm 36.4$ & $*$ \\
\hline Plant feeders & $1659.8 \pm 321.5$ & $721.9 \pm 166.6$ & $*$ \\
\hline & $2187.2 \pm 108.6$ & $1455.8 \pm 161.7$ & $*$ \\
\hline Bacterial feeders & $215.5 \pm 44.4$ & $103.0 \pm 26.6$ & $*$ \\
\hline Predators & $455.9 \pm 91.4$ & $164.3 \pm 60.5$ & $*$ \\
\hline Fungal feeders & $438.8 \pm 124.9$ & $212.2 \pm 99.2$ & $*$ \\
\hline Omnivores & $1325.3 \pm 333.9$ & $727.4 \pm 88.7$ & $*$ \\
\hline Plant feeders &
\end{tabular}

(1) Different from uninvaded control according the Tukey's (HSD) post hoc test (* for $\mathrm{P}<0.05$; ** for $\mathrm{P}<0.01$ ).

Acknowledgement. We thanks Slovak scientific agency VEGA, project No. 2/0018/20 (0.8) and project No. APVV-19-0142 (0.2) of the Slovak research and development agency for financial support of this study. 


\section{Bibliography}

1. Bongers, T. 1990. The maturity index: an ecological measure of environmental disturbance based on nematode species composition. Oecologia 83, 14-19

2. Čerevková, A., Bobul'ská, L., Miklisová, D., Renčo, M. 2019. A case study of soil food web components affected by Fallopia japonica (Polygonaceae) in three natural habitats in Central Europe. J. Nematol. 51, 1-16.

3. Ferris, H., Bongers, T., De Goede, R. G. M. 2001. A framework for soil food web diagnostics: extension of the nematode faunal analysis concept. Appl. Soil. Ecol. 18, 13-29.

4. Jaccard, P. (1908). Nouvelles recherches sur la distribution florale. Bulletin de la Société Vaudoise des Sciences Naturalles 44, 223-270.

5. Shannon, C.E. \& Weaver, W. (1949). The mathematical theory of communication. Urbana, IL, USA, University of Illinois Press.

6. Stoll, P., Gatzsch, K., Rusterholz, H.P., Baur, B. 2012. Response of plant and gastropod species to knotweed invasion. Basic App. Ecol. 23, 232-240.

7. Tanner, R.A., Gange, A.C. 2013. The impact of two non-native plant species on native flora performance: potential implications for habitat restoration. Plant Ecol. 214, 423-432.

8. Yeates, G.W., Bongers, T.D., De Goede, R.G.M., Freckman, D.W., Georgieva, S.S. 1993. Feeding habits in soil nematode families and genera - outline for soil ecologists. J. Nematol. 25, 315-335 